\title{
Through a Glass Darkly: Reflections on Therapist Transformations
}

\author{
Jennifer L. Callahan \\ University of North Texas
}

\author{
Mark Dittloff \\ Oklahoma State University
}

\begin{abstract}
Psychologists are not immune to unfortunate, potentially devastating, life-changing events. The following article explores how a shared event, the loss of a child, impacted 2 different therapists and describes their individual changes in therapeutic perspectives and approaches. Vulnerabilities and lessons of resiliency are presented, with the direct impact on psychological practice discussed. The authors conclude that encountering personal struggles or challenges can have a transforming influence on therapists, including how therapists conceptualize and interact with their clients.
\end{abstract}

Keywords: therapist variables, professional development, stillbirth, bereavement, phase model

On January 15, 1998, we were changed simultaneously by a single event, the loss of our child, in remarkably different ways. Following our loss, we consulted the literature in the hope that an established theoretical framework could provide us with objective guidance toward personal and professional resiliency. Unfortunately, we found very little research and no theoretical framework. The available descriptive literature predominantly focused on detailing resultant distress (for relatively recent descriptive contributions, see Barr, 2004; Säflund, Sjögren, \& Wredling, 2004; Trulsson \& Rådestad, 2004). However, we did not locate investigations specifically focusing on resiliency after experiencing a stillbirth.

Colloquially, the loss of a child is sometimes referenced by parents as the worst imaginable experience. This sentiment, frequently shared with us by well-meaning individuals, coupled with the paucity of available literature, might lead one to conclude that there is no hope for resiliency in parents who have lost a child. However, outside the scant literature on the stillbirth experience, there exist many potentially useful models describing how indi-

Editor's Note. This article was submitted in response to an open call for submissions on the challenges in the life of the psychotherapist. The collection of eight articles presents powerful narratives of experiences about significant personal and transforming situations that have affected professional functioning. These authors describe how their life challenges influenced their professional roles and what can be learned from these experiences as psychotherapists.- $\mathrm{MCR}$

JenNifer L. CAllahan received her PhD in clinical psychology from the University of Wisconsin-Milwaukee. She is an assistant professor in the Department of Psychology at the University of North Texas. Her areas of research interest span the assessment and psychotherapy domains, with particular focus on the development of clinical competencies through education, training, and supervision.

MARK DitTloff received his MS in community human services at the University of Wisconsin-Green Bay. He is a staff clinician at Oklahoma State University with more than 20 years of experience in residential and outpatient settings.

CORRESPONDENCE CONCERNING THIS ARTICLE should be addressed to Jennifer L. Callahan, who is now at the Department of Psychology, University of North Texas, P.O. Box 311280, Denton, TX 76203-1280. E-mail: jennifercallahan@unt.edu viduals in psychotherapy move from distress to resiliency. Some appear less informative with respect to the experience of stillbirth (e.g., Bandura, 1977; DiClemente \& Prochaska, 1982; Jung, as cited in Groesbeck, 1975; Rogers, 1958), but others may be helpful. For example, Uhlenhuth and Duncan (1968) reported that an improved sense of subjective well-being reduces symptom distress, and Frank (1968) emphasized instillation of hope as facilitative of resiliency.

However, Whitehorn's (1959) formulation is perhaps the most appropriate for the purposes of this special section on professional transformations. He proposed that the path to resiliency stems from individuals expecting wellness, then feeling well and, finally, working well. In essence, Whitehorn's model implies that optimal professional functioning may not be attained if personal distress is not effectively addressed.

More recently, this idea has been supported by the meta-analytic findings generating the phase model of psychotherapy (Howard, Lueger, Maling, \& Martinovich, 1993). According to the phase model, resiliency is fostered in a predictable manner, with each sequential phase contingent on progress being made in the previous phase. In particular, the phase model indicates that resilient individuals must first experience improvement in their subjective sense of well-being before they can expect to experience relief from distressing symptoms (e.g., decrease sleep disruption, excessive rumination). Finally, after these phases are accomplished, individuals are able to effectively resume their former level of role functioning (e.g., doing well at work).

It is important to note that neither Whitehorn (1959) nor the authors of the phase model were attempting to describe resiliency in a nonclinical population. However, on the basis of our experiences as detailed in this article, we believe their conceptualizations of resiliency in the face of clinically significant distress provide a useful framework for understanding therapist transformations that may follow personal tragedy. Because our article specifically illustrates this framework in the aftermath of having a stillborn child, the general themes suggested by both Whitehorn and the phase model may be salient to a wide range of loss experiences and other personal tragedies.

In this article, we both acknowledge struggling to develop a sense of well-being, experiencing a range of distress, and, ultimately, being changed as professionals. Yet, although we shared 
the same devastating event, our experiences and the impact professionally were distinct. In part, this likely reflects some preexisting professional differences in theoretical orientations (Jennifer L. Callahan has a cognitive-behavioral orientation, whereas Mark Dittloff has a family systems orientation). However, it also clearly reflects other preexisting, nonprofessional individual differences as well as differences in our experience of the loss of our child. In the sections that follow, each of us describes our personal experience of loss to illustrate how demoralization set in, recount the struggle to then attain subjective well-being, and provide a sampling of the symptoms of distress evidenced by each. Together, these are meant to provide a context for the subsequently presented professional transformations identified by each of us.

\section{Context From a Mother's Perspective}

\section{Denial}

Fully 9 months pregnant, I had been told for nearly 7 weeks that labor could begin "any day," and I was as prepared as I thought I could be to experience the birth of my first child. While I was en route to the hospital, my physical distress seemed atypical, but I experienced a sudden, marked improvement once we arrived. Thinking myself an intellectual, I silently praised what (I thought) was an insightful observation that placebo effects were causing me to deal with labor more effectively.

As the nurse attached the fetal monitor, she struggled to find my baby's heartbeat. She called for a portable ultrasound, reassured us that the machine had been malfunctioning that day, and apologized repeatedly for making us wait as a physician was awoken to evaluate me. When the physician arrived, I noticed that he had trouble adjusting to the glare of the ultrasound monitor and was compensating by rubbing his fatigued eyes. I felt sorry for him.

\section{Reality Hits}

I am sure the physician must have introduced himself when he came into the room. But, frankly, I did not particularly care. He was not my attending physician; he was just someone to get me checked in-transitional and of no consequence. Transitional doc turned out to be the person who would utter the most important words I have ever heard: "I'm sorry; your baby has died." It was 5:30 a.m. Samantha Taylor Dittloff had passed.

\section{Immediate Aftermath}

Improbably, the phone in my hospital room was broken, and we did not have a cell phone. My husband had to leave to make the notification calls to family from a public phone in the hospital hallway. The nurses and transitional doc took that cue to exit around 5:35 a.m. Somewhere between then and 8:00 a.m., while pondering the meaning of everything, I had an immediate personal understanding of suicide.

I was suddenly aware of how pain can reach such an intolerable level that remission is unfathomable. In fact, this was so palpable to me that I was actually stunned that the medical personnel were leaving me alone with so many self-destructive resources available. As I considered my options, I concluded that such an act would invalidate my daughter. Without me to remember her, it would be as if she had never existed. In that moment, a mother was born.

Just as I had decided that continuing to breathe was my only useful option, the attending physician arrived and ordered a volume of tests, reluctantly explaining that I was at a heightened risk for death during delivery. I could not have cared less. Six hours later, Samantha arrived in a delivery that, to most, would have appeared quite typical until the deafening silence when a first cry should have sounded. Now the nurses referred to me as a mother, too.

\section{Maternal Rage}

The state I lived in did not agree with my status as a mother. There was no mistaking its position on the matter of motherhood. I could not possibly be a mother because I did not have a child. The proof was the lack of a birth certificate (only issued for live births). Without a birth certificate, there could be no certificate of death. As a result, in the eyes of the state, my child never existed, and I was not a mother. Coming to grips with that reality allowed for the first of many professional transformations.

\section{Lessons Learned From a Mother's Perspective}

It is impossible to consider all the personal and professional transformations, but those that may be most useful to a range of professionals or are particularly salient are included here. Some of the transformations presented are intertwined, whereas others represent independent lines. For the sake of clarity, the transformations are clustered along the phase model framework: well-being, symptomatic distress, and social and professional role functioning.

\section{Lessons Regarding Subjective Well-Being}

Given that my theoretical orientation at that time was predominantly cognitive-behavioral, it is probably not surprising that one of the earliest lessons I appreciated was that cognitive distortions can be truly adaptive. This appreciation was a result of a realization that the belief "I am a mother" provided me with safety during a time when I was vulnerable to poor decision making. The state's regulations made it clear that this belief was not shared by the majority. I am thankful that no one pointed that out to me at the time, because I would have been hard pressed to identify an alternative belief that could have effectively allowed maintenance of personal safety.

As a result of this lesson, my in-session behavior has changed. I now more fully seek to appreciate the many functions that a belief serves, even if evidence contrary to the belief seems readily apparent (see Beck, 1995, for a discussion on the relevance of evaluating the utility of automatic thoughts). A belief, even if not entirely rational, that provides hope when it is needed or enhances the subjective sense of well-being is sometimes best left intact, at least temporarily, because of its potential utility in promoting long-term resiliency.

\section{Lessons Regarding Distress}

Although this may be the area in which most of my lessons seem concentrated, three lessons seem potentially more generalizable to 
other clinicians experiencing personal tragedy of some sort: (a) Loss can be an ongoing experience that never fully remits, (b) acute pain may be recurrent and compound the ongoing loss at times, and (c) social comparison can be very unhelpful. Each of these is addressed in turn.

Loss is ongoing. Sometime after Samantha died, I learned that during prenatal ovary development, the germinal cells that mature into eggs are already formed (Faddy, 2000). I had not previously realized that the potential of future grandchildren had existed before her death, and when I learned that, a new loss was realized. Other moments of loss are more mundane but no less significant. I cannot count the number of times when I have wished for the opportunity to witness Samantha showering her little sister with love or the opportunity to negotiate the inevitable sibling bickering that might have been.

Acute pain may be recurrent. Aside from such chronic pain, there are moments of acute pain that may be long separated from the initial loss. Following the birth of my second child, Alexandra (nicknamed Ali), I realized that she, too, would be hurt by Samantha's death. Watching Ali grow to understand what death means, being unable to answer many of her questions, and seeing her pain at realizing what she personally lost in her sister's death were nearly as painful to me as the initial loss itself. Of course, I could not fix Ali's pain, and she came to prematurely realize that Mommy is not omnipotent and cannot truly guarantee her safety. Her insight caused us both pain.

The lessons on acute and ongoing pain have jointly influenced my practice with bereaved individuals (clients or not). In particular, I am much more attentive to the importance of remembering. I am careful to reference the deceased by name, to show that I remember and that the loss is important to me. In remembering, I also hope to convey approachability so that my clients will alert me to acute feelings of loss that may surface and not feel as though they need to protect me from their pain.

Social comparison can be very unhelpful. There is little literature devoted to the experience of a subsequent pregnancy after loss (e.g., Barr, 2004; Säflund et al., 2004; Trulsson \& Rådestad, 2004), and I stumbled on an online listserv devoted to this topic while pregnant with my second child. Unfortunately, as occasionally happens on listservs, charged emotions erupted one day. Essentially, it came down to a battle over what type of loss qualified as the most painful. Some argued passionately that a miscarriage was the most painful loss because one never saw one's child. Equally passionate replies said that stillbirth was the worst because it was the loss of a fully formed and delivered infant. Others noted that parents who had endured miscarriages and stillbirths were "lucky" because they did not have to witness painful medical procedures inflicted on an infant destined to die. The postings were increasingly lengthy and desperate for validation, and no winner reigned.

As a therapist, I learned from this experience that attempting to hierarchically arrange pain is useless. Pain is entirely subjective, and nothing good can come from accusations that some pain is more deserving of attention than others. In my view, people do not typically (I do, of course, acknowledge exceptions) bother coming into my office unless they are in pain. For me to determine that the person engaged in an existential search for meaning is not a real client worthy of an empirically based treatment is to invalidate that person's subjective experience of the pain associated with his or her living. This not only impacts my approach as a therapist, it also impacts my approach as a scholar and researcher. All pain is worthy of efforts at providing relief.

\section{Lessons Regarding Professional Role}

Defining success. An advocate for the importance of clinical expertise, I faithfully track progress at each session with my clients, actually examine the data each time, and make adjustments to the course of treatment provision. I adhere to the typical convention of expecting the amount of change to exceed the reliable change index and cross from a clinical range into a nonclinical range (Jacobson \& Truax, 1991). It is easily done and known to improve outcomes (Lambert, Harmon, \& Slade, 2005) in aggregate analyses. Personally, I have found that it works for me, and my "success" rate across settings is one that allows me to sleep reasonably well at night. But I now am able to recognize that this is not actually success. My personal experiences have resulted in my becoming a much more humble therapist.

I now understand that some things never get better and that full recovery is not possible for, or even desired by, all clients across all situations. Although I continue to use my objective measures to track progress, I now do a better job of realizing that indexes for determining clinically significant change (e.g., Jacobson \& Truax, 1991) do not have a quantitative provision that accounts for client priorities or values. This is an unfortunate oversight and a quantitative challenge that researchers should consider carefully.

Phenomenology versus reality. As a young clinician working mostly with juvenile sexual offenders, I typically valued reality and facts as embodying "the truth" (Ryan \& Lane, 1997) and was comfortable describing myself as having a cognitive-behavioral orientation. However, without necessarily meaning to change, I found that after Samantha's death, a shift in my thinking occurred. I now feel a bit unsettled when faced with a simple inquiry regarding my orientation because I do not have a quick, convenient label to apply (in my defense, the data suggest this is more common than not; Norcross, Hedges, \& Castle, 2002).

When I reflect on my personal experience, it is clear to me that my phenomenological perspective of what was happening was more salient to my understanding of the moment than were the actual facts. For example, although I noticed that transitional doc was rubbing his eyes excessively, the fact - the truth-that my child had died and that the doctor was struggling with how to tell me never crossed my mind. Rather, the truth to me, in that moment, was that we were making the requisite preparations for the delivery of a healthy and happy baby. At that moment, objective reality and my truth seemed an insurmountable distance apart. I now strive to understand my clients' phenomenological experience of their lives and defer my judgment of what is rational until I am able to appreciate their very personal but subjective referencing perspective.

I am always a psychologist (whether I feel like one or not). As I grew into a professional identity, I learned to be mindful that I am viewed as a psychologist wherever I go. But I am also still myself wherever I go; sometimes it is confusing to be both simultaneously. For me, the best illustration of this is the unavoidable necessity of getting my hair cut. Without fail, the question comes up, "Do you have children?" The other requisite question is, "What do you do for a living?" When people put it together that I am a 
psychologist whose child has died, uneasiness sets in. I have heard a plethora of responses, but too often something is said that implies an expectation that I am above personal pain because I am a psychologist. This causes me not to lose sight of the continuing stigma attached to emotional distress, in any of its forms, and I consequently aim to be a better citizen psychologist in combating such stigmas.

\section{Context From a Father's Perspective}

Some moments in life irrevocably change you in unfathomable ways. On January 15, 1998, fate decided to take a hand. I went to the hospital believing I would be returning with my child. Instead, I returned home to plan a funeral. The 3 days immediately after Samantha's death remain a blur, and, in fact, much of the year following her death is still sketchy. I mostly remember what occurred during those 3 days but not in a linear or chronological order. Instead, those days blend together into one long, surreal day. In some ways, Samantha has become my greatest teacher about life-and about therapy.

\section{Immunity Lost}

I remember the on-call resident looking sleepy that night as he entered the room to obtain a sonogram because the nurses could not find Samantha's heartbeat. As he searched the monitor screen, looking for any sign of life, I noticed tears in his eyes. Although I was not fully aware of what had happened, I had begun to surmise that something was wrong. Finally, with the tears still in his eyes, he told us how sorry he was that our baby had died. Samantha's life was over before it had begun, and there was nothing, as her father, that I could do about it. I began repeating over and over again that everything would be all right. Whether it was shock or denial, I could not have been more wrong.

\section{Men Cry, Too}

I wanted to cry, but I had the irrational belief that I needed to be strong for Jennifer and that crying in front of her would undermine my illusion of strength. So I told her that I needed to leave to make some phone calls, despite the fact that it was very early in the morning. I decided to call my brother first, and, on telling him of Samantha's death, I began to sob. Hearing me cry (at that time a rare occurrence, although sometimes I feel like I have not stopped crying since Samantha's death) triggered my brother's need to comfort me, which culminated in him telling me that Jen and I could have more children. I do not think that he has forgiven himself to this day for that statement, although I never took offense to it. I was too focused on not having Samantha to think about having more children.

Next, I called my parents. My father answered the phone, and I again began to sob as I told them of their granddaughter's death. My father was shocked and did not know how to comfort me. He just kept repeating, "Oh, Mark," over and over again. Finally, I called Jennifer's parents. Her mother answered the phone and asked, "Do you have good news for me?" at which time I began to cry again, leading her to cry. For several years after Samantha's death, I had flashbacks of those phone calls, as I am having now as I write about them.
After Samantha's death, several friends and couples who were pregnant and aware of our loss chose not to get in touch with us. One friend later explained that even though he knew better, he still felt as though something bad might happen to his unborn child if he contacted us. Although I was somewhat hurt and mystified at the time, his later explanation was much appreciated. As a result, Jen and I do not to talk about Samantha and her death with couples we know are pregnant or actively trying to become pregnant. It simply increases their anxiety level during a time when they are already anxious.

\section{Lessons Learned From Father's Perspective}

Years before I met my wife, a friend and I engaged in a philosophical discussion about how a person's personal philosophy of life affects the decisions he or she makes. I told my friend that I did not believe in losing; be it talent, wit, work ethic, or patience, I would find a way to win. To quote Captain James T. Kirk from Star Trek, "I don't believe in no-win scenarios" (Bennett \& Meyer, 1982). When I was done, my friend calmly explained to me that I could afford this belief because I had never lost. One way or another, I had always gotten what I wanted, and I left that conversation arrogantly clinging to my belief that I was in control of my life and would simply never allow myself to lose.

\section{Lessons Regarding Subjective Well-Being}

Samantha's death challenged the very foundation of my personal philosophy. I was rendered vulnerable for the first time in my life. I had lost something priceless and had been powerless to stop it from occurring, which created an existential crisis for me. What I believed to be true about life was now under question. I wondered whether I had been wrong about the rules governing life. If so, had I been perceiving situations wrongly my whole life? If I was not perceiving reality accurately, how could I trust myself to draw the right conclusions in the future? Suddenly, nothing that I had thought I knew was certain. However, I was now acutely aware of the true meaning of being powerless and without control. It was frightening, and it took me awhile before I realized that my beliefs still had merit and that Samantha's death was an aberration. She is and will always be my daughter. She is a part of my life, and her death is a part of who I am, but I cannot allow her loss to exclusively define me, and I do not believe that Samantha would want it to do so.

Having my personal philosophy of life challenged had a profound impact on my therapy. I am now more compassionate and empathetic as a therapist. I understand how life's pitfalls can be neither earned nor deserved. And I have learned that none of us is exempt from the trials of life. I have learned that power is an illusion and control a mirage. Consequently, first and foremost, I meet my clients as people. I have learned that when an individual's fundamental basis for well-being is gone, everything else is adrift.

I like to talk about Samantha; talking about her helps keep her alive for me. Over the years, I have paid tribute to her in a variety of ways. I wore a pearl earring and an angel pin (to work) for 5 years after her death. Jen and I both kept a picture of Samantha in our offices and continue to wear a Black Hills gold baby ring on a chain around our neck; Samantha was buried wearing an identical one. Throughout the years, several clients have commented 
on my dedication to keeping the memory of Samantha alive. The impression they conveyed to me was that they felt that my loyalty to Samantha boded well for the loyalty that I would give to them in case our work together was not going well.

\section{Lessons Regarding Distress}

Blame. It is interesting that Jennifer and I found it easier to blame ourselves for Samantha's death than each other, even though the cause of her death was never determined. Over time and many discussions, it became apparent that taking the blame implied that we had some control over the situation and thereby made her death easier to accept (Barr, 2004). In working with clients, I find that I am now better able to understand why survivors may irrationally blame themselves for abuses inflicted on them.

We decided that we could not afford to blame each other for Samantha's death, and unintentionally, we began to narrate a meaning that would help us understand losing her. In that process, I learned that trauma survivors can benefit from being mindful of the stories they tell themselves. I cannot tell a survivor what meaning to derive from his or her experience, and I would have been deeply offended if anyone had told me what I should be thinking or feeling about Samantha's death. But, as a therapist, I can help survivors create their own narrative to make sense of what occurred.

Anger. A few years after Samantha's death I realized that I was angry with her. I had always said that I would have done anything to save her, and one day, I began to wonder whether she had fought hard enough to live. I missed her so much but was also angry at her for ruining my plans to be her father. Angry at not getting what I wanted, I also felt a great deal of guilt at even being angry, and I became aware of how hard it is to express anger toward a loved one who has died. My personal difficulty expressing, and my guilt for feeling, anger has led me, at times, to overtly give grieving clients permission to be angry at their deceased loved one as a facilitative avenue in addressing the myriad emotions of loss.

Grief. One night a favorite movie of mine, To Kill a Mockingbird, was on TV. As the movie began, I started to cry and could not stop. I had planned to read this book to Samantha, and it was not until the movie came on TV that I realized I would never do so. Overwhelmed by grief, I concluded that grieving is more for the self than for the deceased. My grief that evening was about all the things I had planned on but would not do with Samantha.

This situation taught me several things. First, grieving is not a linear process. The person grieving never knows exactly when or where something will trigger the grieving process. As a result, I have learned to encourage clients to experience the feelings these situations trigger as they occur. Second, grieving is not a nice, neat package with a 6-month duration, as the diagnostic criteria of the Diagnostic and Statistical Manual of Mental Disorders (4th ed., American Psychiatric Association, 1994) would have one believe. For me, the 1st year was awful. It seemed as if everywhere I went, there was a baby; I never noticed so many babies in my life, and every time I turned around there was some type of anniversary for Samantha.

Fear. After Samantha's death, I told my wife I was no longer interested in having children. I was not willing to go through another pregnancy, afraid that I would not survive having another child die. Because the cause of Samantha's death was never determined, it seemed likely it would occur again, and I knew I would feel completely powerless throughout another pregnancy. I changed my mind because I realized that I had never allowed fear to make decisions for me and did not want to set that precedent. However, after Ali was conceived, I developed a full-blown anxiety disorder, as I had feared, and my anxiety manifested in alternate bouts of crying and temper tantrums. All I could do was wait, a behavior for which I am not well suited, and nothing I did to deal with the anxiety seemed to help. My anxiety culminated one Saturday afternoon when I demolished my bicycle against a concrete wall because I could not adequately repair a flat tire.

Jennifer's pregnancy with Ali taught me about the fear of the unknown, and my empathy for my clients with anxiety disorders deepened considerably. I became more patient with clients who were working hard with few results to show for it. I understood their frustration at not seeing results quickly and how this can lead a person to self-doubt and loathing. I could explain, from firsthand knowledge, that attempting to avoid anxiety is not effective, and I encouraged my clients to take advantage of the literature on anxiety management (e.g., Simpson \& Liebowitz, 2006).

I also learned that although most survivors of trauma are acutely aware of how their experience has impacted their ability to trust other people, many seem to be unaware of their fear of trusting themselves. In my opinion, resolution of this fear is of paramount importance to resolving other trauma-related issues. Many clients are surprised when I bring this up because it is something they had never considered. Similarly, when exploring how trauma or victimization has changed their decision-making process, clients are often surprised at the extent of the ongoing disruption. In fact, this is often where I choose to begin our work together: rebuilding their trust in their own decision making. Only when this issue is resolved can we effectively move on to work on rebuilding their trust in others.

\section{Lessons Regarding Professional Role}

Helplessness can lead to avoidance. After learning of Samantha's death, my wife and I were left alone in the delivery room for several hours. We found out later the hospital personnel were waiting for a nurse with bereavement training to arrive. In retrospect, it is apparent that even though they were professionals who had certainly encountered death previously, they did not know what to say to us. This seems especially true when someone considers the loss to be particularly sensitive. Unfortunately, the corresponding feeling of helplessness can be used to justify staying away. This experience has reinforced my belief that all clients should be given unconditional regard by therapists and my belief that simply being with clients is important (Rogers, 1958).

Setting boundaries. Unfortunately, I worked on commission at that point in my professional career, and I had to return to work 10 days after Samantha's death. Most of my clients had learned of Samantha's death and wanted to talk about it in our first session together afterward. As a result, I told Samantha's story countless times. Most of my clients were compassionate and supportive. However, several clients were angry and fo- 
cused on how Samantha's death had been a problem for them (e.g., rescheduled sessions.). They seemed to want to hurt me while I was vulnerable and were decidedly nasty in expressing their feelings.

I found myself having to set boundaries with both types of clients. Those who were compassionate and supportive still needed to know that they were the focus of our sessions together. Those who were less than supportive needed to know they had hurt my feelings and that the means they had chosen to express their feelings were unacceptable if they wanted to continue working with me. For me, therapy is relationships first, issues second, and technique a distant last.

The importance of social support. The fact that I was working on commission and faced with enormous medical bills also meant that I had to be at work at all times of the day and evening in case a potential client called. Tired and hungry, when I finally got home I simply wanted to avoid thinking or feeling for the rest of the evening. However, Jennifer wanted to talk about Samantha. I did not want to talk about such an emotional subject so late in the day, but I knew I had to push through my fatigue and listen. In these talks, Jennifer and I began to refer to "Samantha days." On these days something would happen to trigger our grieving, which, once begun, would often last the entire day. Sometimes it would be something that happened on my way to work, and on my arrival, I would close my office door, sit down at my desk, and cry. But by recognizing the importance of talking and setting time aside to do so no matter how tired we were, Jennifer and I were able to use each other extensively for support when we were having a particularly bad Samantha day.

This process reawakened my understanding of how important listening is in the communication process (Rogers, 1958), and I rededicated myself to truly listening to my clients. It also led me to keep a closer eye on the listening skills of couples in treatment. Being a loner, I do not think that I had previously ever completely appreciated having the support of people I care about. Talking with Jennifer about the loss of Samantha made her loss more tolerable. We could empathize with each other, which led me to begin asking clients about their support networks and, if they reported none, to help them to develop them.

\section{Conclusion}

The death of our child changed each of us personally and professionally in distinct ways. In writing this article, we began separately to better illustrate the individual differences that can result from even shared experiences. Yet some commonality is evident in the resultant narratives. For example, both of us point to the role of positive social support as potentially facilitative of resiliency (Brewin, Andrews, \& Valentine, 2000; Frazier, Tashiero, Berman, Steger, \& Long, 2004; Ozer, Best, Lipsey, \& Weiss, 2003), whereas negative social support can be damaging (Borja, Callahan, \& Long, in press). Each of us notes the importance of clinicians assessing the presence and quality of social support in clients' lives as a part of treatment. In addition, we both acknowledge the resurgence of pain or grief over time and, both recommend that those who work with grieving individuals strive to create an approachable demeanor for such resurgences and note that deliberate but gentle remembering of the loss may help to foster approachability.
The narratives also reveal individual experiences. Some of the differences may be due to obvious gender and parental role differences, but others are of less clear etiology (e.g., change in personal philosophy, suicidal ideation). Clinicians are encouraged to remember that their clients are individuals within a context and not presume to fully understand the nature of the clients' experience on the basis of their own personal set of experiences, an aggregate data set, or other possible sources of bias or error.

Finally, within the lessons learned, both of us describe experiences that seem to support the resiliency framework of the phase model. However, the sections providing each author's perspective of loss imply that the phase model may also be suited to describing the process by which clinically significant distress emerges. Both of us describe a dramatic, seemingly instantaneous drop in subjective well-being with resultant varied symptomatic distress impacting our professional role functioning. We encourage future research examining this possibility.

\section{References}

American Psychological Association. (1994). Diagnostic and statistical manual of mental disorders (4th ed.). Washington, DC: Author.

Bandura, A. (1977). Self-efficacy: Toward a unifying theory of behavioral change. Psychological Review, 84, 191-215.

Barr, P. (2004). Guilt- and shame-proneness and the grief of perinatal bereavement. Psychology and Psychotherapy: Theory, Research and Practice, 77, 493-510.

Beck, J. S. (1995). Cognitive therapy: Basics and beyond. New York: Guilford Press.

Bennett, H. (Producer), \& Meyer, N. (Director). (1982). Star Trek II: The Wrath of Kahn [Motion picture]. United States: Paramount Pictures.

Borja, S. E., Callahan, J. L., \& Long, T. (in press). Positive and negative adjustment and social support of sexual assault survivors. Journal of Traumatic Stress.

Brewin, C. R., Andrews, B., \& Valentine, J. D. (2000). Meta-analysis of risk factors for posttraumatic stress disorder in trauma-exposed adults. Journal of Counseling and Clinical Psychology, 68, 748-766.

DiClemente, C. C., \& Prochaska, J. (1982). Self change and therapy change of smoking behavior: A comparison of processes of change in cessation and maintenance. Addictive Behaviors, 7, 133-142.

Faddy, M. J. (2000). Follicle dynamics during ovarian aging. Molecular and Cellular Endocrinology, 163, 43-48.

Frank, J. D. (1968). The role of hope in psychotherapy. International Journal of Psychiatry, 5, 383-395.

Frazier, P., Tashiero, T., Berman, M., Steger, M., \& Long, J. (2004). Correlates of levels and patterns of positive life changes following a sexual assault. Journal of Consulting and Clinical Psychology, 72, 19-30.

Groesbeck, C. J. (1975). The archetypal image of the wounded healer. Journal of Analytical Psychology, 20, 122-146.

Howard, K. I., Lueger, R. J., Maling, M. S., \& Martinovich, Z. (1993). A phase model of psychotherapy outcome: Causal mediation of change. Journal of Consulting and Clinical Psychology, 61, 678-685.

Jacobson, N. S., \& Truax, P. (1991). Clinical significance: A statistical approach to defining meaningful change in psychotherapy research. Journal of Consulting and Clinical Psychology, 59, 12-19.

Lambert, M. J., Harmon, C., \& Slade, K. (2005). Providing feedback to psychotherapists on their patients' progress: Clinical results and practice suggestions. Journal of Clinical Psychology, 61, 165-174.

Norcross, J. C., Hedges, M., \& Castle, P. H. (2002). Psychologists con- 
ducting psychotherapy in 2001: A study of the Division 29 membership. Psychotherapy: Theory, Research, Practice, Training, 39, 97-102.

Ozer, E. J., Best, S. R., Lipsey, T. L., \& Weiss, D. S. (2003). Predictors of posttraumatic stress disorder and symptoms in adults: A meta analysis. Psychological Bulletin, 129, 52-73.

Rogers, C. R. (1958). A process conception of psychotherapy. American Psychologist, 13, 142-149.

Ryan, G. D., \& Lane, S. L. (1997). Integrating theory and method. In G. D. Ryan \& S. L. Lane (Eds.), Juvenile sexual offending: Causes, consequences, and correction (2nd ed., pp. 267-321). San Francisco, CA: Jossey-Bass.

Säflund, K., Sjögren, B., \& Wredling, R. (2004). The role of caregivers after a stillbirth: Views and experiences of parents. Birth: Issues in Perinatal Care, 31, 132-137.

Simpson, H. B., \& Liebowitz, M. R. (2006). Best practice in treating obsessive-compulsive disorder: What the evidence says. In B. O. Roth- baum (Ed.), Pathological anxiety: Emotional processing in etiology and treatment (pp. 132-146). New York: Guilford Press.

Trulsson, O., \& Rådestad, I. (2004). The silent child: Mothers' experiences before, during, and after stillbirth. Birth: Issues in Perinatal Care, 31, 189-195.

Uhlenhuth, E. H., \& Duncan, D. B. (1968). Subjective change with medical student therapists: Some determinants of change in psychoneurotic outpatients. Archives of General Psychiatry, 18, 532-540.

Whitehorn, J. C. (1959). Goals of psychotherapy. In E. A. Rubinstein \& M. B. Parloff (Eds.), Research in psychotherapy (pp. 1-9). Washington, DC: American Psychological Association.

Received May 31, 2006 Revision received September 27, 2006 Accepted September 27, 2006

\section{Call for Nominations}

The Publications and Communications $(\mathrm{P} \& \mathrm{C})$ Board of the American Psychological Association has opened nominations for the editorships of Psychological Assessment, Journal of Farnily Psychology, Journal of Experimental Psychology: Animal Behavior Processes, and Journal of Personality and Social Psychology: Personality Processes and Individual Differences (PPID), for the years 2010-2015. Milton E. Strauss, PhD, Anne E. Kazak, PhD, Nicholas Mackintosh, PhD, and Charles S. Carver, $\mathrm{PhD}$, respectively, are the incumbent editors.

Candidates should be members of APA and should be available to start receiving manuscripts in early 2009 to prepare for issues published in 2010. Please note that the P\&C Board encourages participation by members of underrepresented groups in the publication process and would particularly welcome such nominees. Self-nominations are also encouraged.

Search chairs have been appointed as follows:

- Psychological Assessment, William C. Howell, PhD, and J Gilbert Benedict, PhD

- Journal of Family Psychology, Lillian Comas-Diaz, PhD, and Robert G. Frank, PhD

- Journal of Experimental Psychology: Animal Behavior Processes, Peter A. Ornstein, PhD, and Linda Porrino, $\mathrm{PhD}$

- Journal of Personality and Social Psychology: PPID, David C. Funder, PhD, and Leah L. Light, $\mathrm{PhD}$

Candidates should be nominated by accessing APA's EditorQuest site on the Web. Using your Web browser, go to http://editorquest.apa.org. On the Home menu on the left, find "Guests." Next, click on the link "Submit a Nomination," enter your nominee's information, and click "Submit."

Prepared statements of one page or less in support of a nominee can also be submitted by e-mail to Emnet Tesfaye, P\&C Board Search Liaison, at etesfaye@apa.org.

Deadline for accepting nominations is January 10, 2008, when reviews will begin. 